\title{
اتجاهات طلبة التعليم الأسـاسي والثانوي قي الأردن نحو التعلّم عن بُعد وتحدياته في ظل جائحة كورونا (COVID-19)
}

\author{
صبرين محمود السلمان \\ أخصائية تدريب- أكاديمية الملكة رانيا لتدريب المعلمين-عمان- الأردن \\ s.salman@qrta.edu.jo \\ علي خالد علي بواعنه \\ أستاذ مسـاعد- عمادة تطوير التعليم الجامعي- جامعة الامام عبد الرحمن بن فيصل- المملكة العر بية السعودية \\ akbawaneh@iau.edu.sa
}

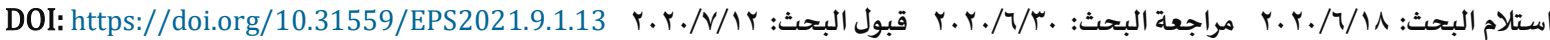

هدفت الدراسـة إلى استكشاف اتجاهات طلبة التعليم الأساسي والثانوي في الأردن نحو التعلّم عن بُعد وتحدياته والحلول المقترحة في ظل جائحة كورونا (COVID-19)، وتكّون مجتمع الدراسة من جميع الطلبة الأردنيين في مرحلة التعليم الأسـاسي والثانوي من كافة الأقاليم.

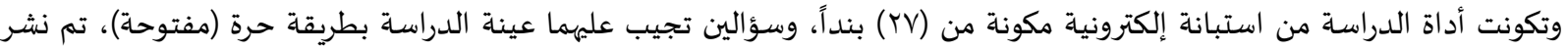

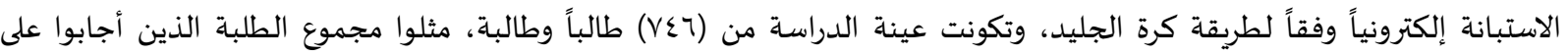

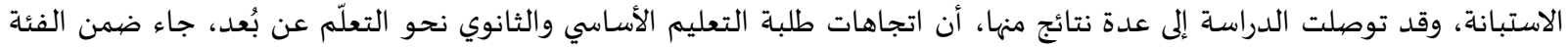
المتوسطة، وبمتوسط حسابي مقد اره (r,09) وبنسبة مئوية قدرها (.7\%)، في حين جاءت التحديات والمشكلات التي تواجاء الطلبة في التعلّم

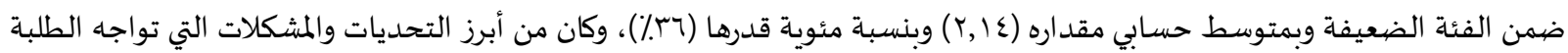

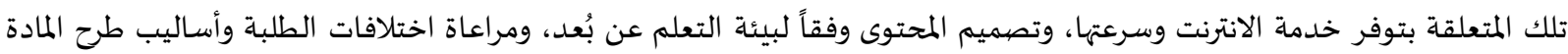

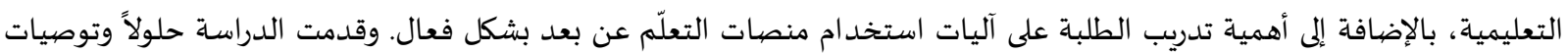

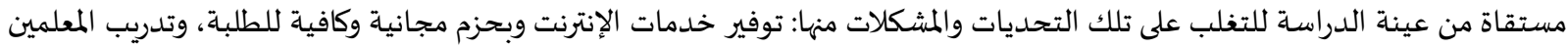
والطلبة على كيفية استخدام منصات التعلّم عن بُعد، وتنظيم الوقت والدروس الخاصة بالتعلم عن بعد، وأوصت الدراسة عدة تورة توصيات منها، إعادة تصميم المحتوى التدريسي وفقاً لنماذج ونظريات التعليم والتعلّم عن بُعد وآليات تقديمها بشكل أفضل، وتزويد المدارس ببنى تحتية مناسبة وأدوات ومصيادر كافية لتمكنها من تطبيق متطلبات التعلم والتعليم عن بعد.

الكلمات المفتاحية: التعلم عن بعد؛ اتجاهات الطلبة؛ مشاكل وحلول التعلّم عن بعد؛ التعلم في ظروف استثنائية؛ والتعلم خلال جائحة COVID 19

يشهد العالم حالياً تطوراً تكنولوجيا هائلاً وسريعاً لم يشهده من قبل في نواح متعددة، مما جعلنا لا نستطيع الاستغناء عن التكنولوجيا الحديثة

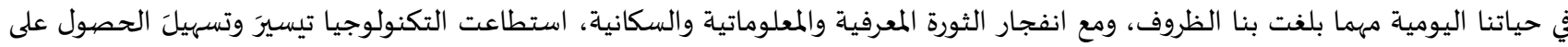

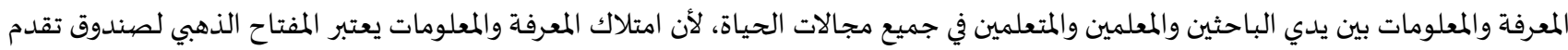

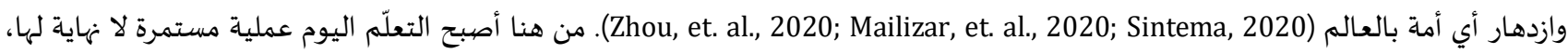




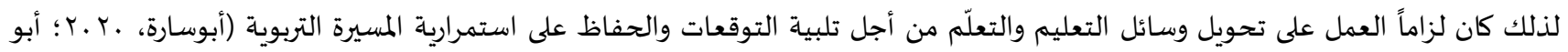

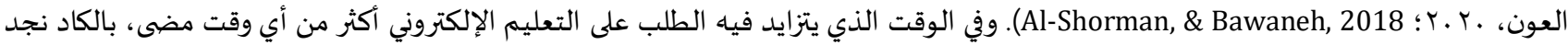

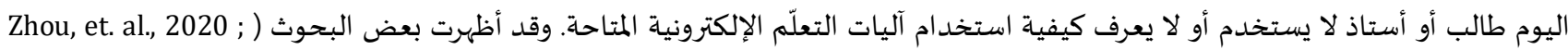
(Saavedra, 2020 التي ركزت على التعلّم من خلال بيئات التعلّم الافتراضية أن التربويين ينظرون إلى هذا النوع من التعليم كوسيلة للوصول إلى عدد أكبر من الطلبة، إلا أن الأساتذة يعانون من عبء العمل الكبير جراء التوقعات العالية من الطلبة الذين أعربوا من ناحية أخرى عن تقديرهم للفرصية التي تتيحها بيئات التعلّم الافتراضية، حيث يتم التعليم بطريقة أكثر استقلالية من قيود الزمان والمكان، وبعيداً عن التعليم التقليدي في القاعة مناء

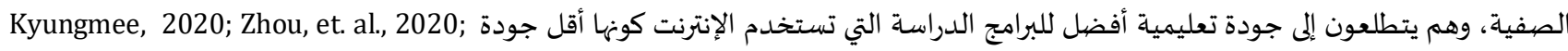

.(Hu, 2019; Huang, 2018)

ومع التقدم التقني الكبير وانتشار الإنترنت، وظهور العديد من المستحدثات التكنولوجية في المجال التعليمي، والتي أصبحت محور الاهتمام من

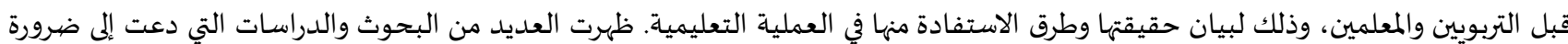

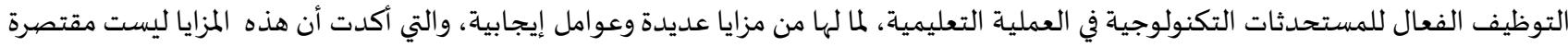

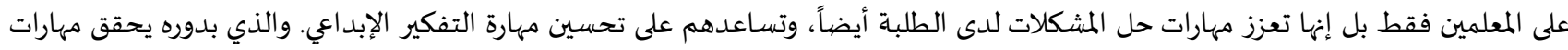
القرن الحادي والعشرين، ويراعي مصالح المتعلمين باعتبارهم محور عملية التعليم ومركزها، خاصةً في عصرنا هذا الذي يطلق عليه العصر التكنولوجي مهابي

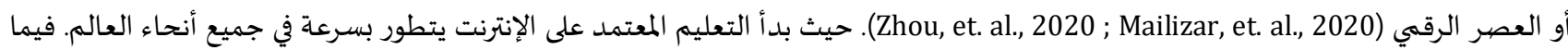
تسعى مؤسسات التعليم باستمرار إلى توظيف التقنيات الجديدة لتصبح أكثر إنتاجية لإدارة استراتيجيات التنمية التي تتبناها، هذا بالإضافة إلى إعادة

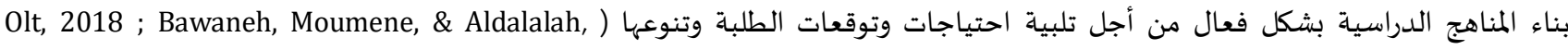
(Adams Becker et al. 2018; 2020

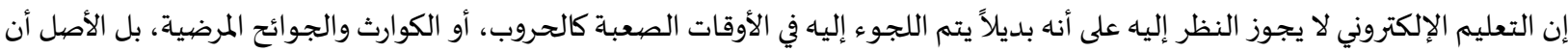

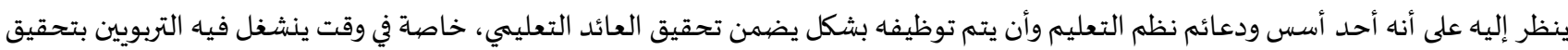
منطلقات جديدة كدور التعليم في تحقيق التنمية المستدامة وتنفيذ الرؤى الطموحة للدول (Saavedra, 2020 (Olt, 2018 ). وفي أوقات الأزمات والمصاعب تهرع كل الأيدي والعقول إلى البحث عن بد ائل في كافة المجالات للتغلب على تلك الأزمات وتفادي أضرارها، والتعليم أحد أهم هذه المجالات

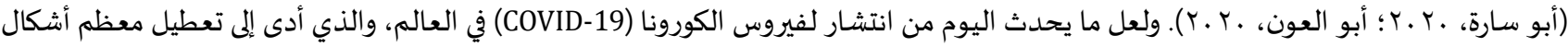

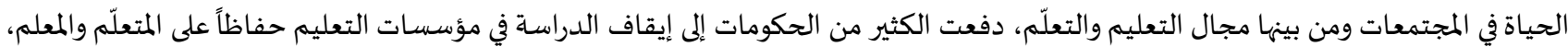
ودفعاً لهذا الضرر نادت أصهواتًا عدة إلى البحث عن بدائل يمات يمكن أن تستمر بها عملية التعلّم مع مراعاة البعد والظرف الذي يعيشهـ العالم اليوم. وأجبر

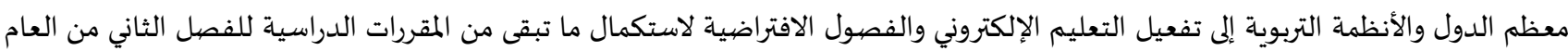

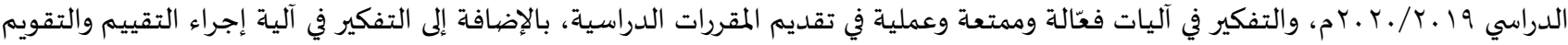

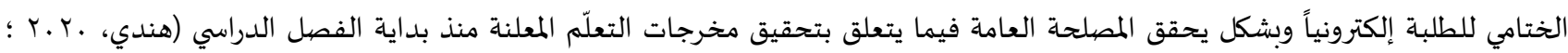

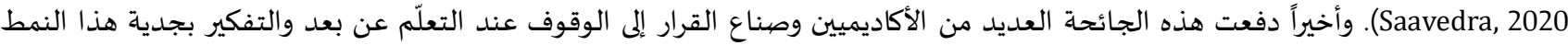

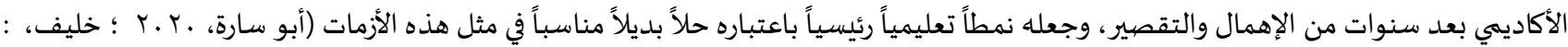

(Zhou, et. al., 2020; r. r.A

وعلى الرغم من الإيجابيات العديدة للتعليم والتعلّم الإلكتروني، إلا أن التحول المفاجئ للتدريس عن بُعد خلال جائحة كورونا 19 أدى إلى صدمة

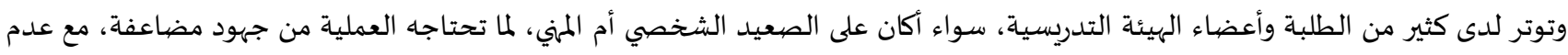

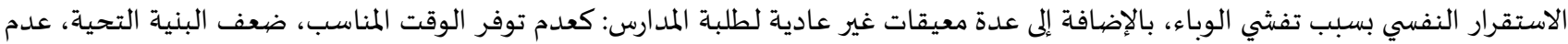

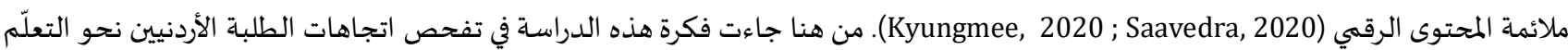
عن بعد والتعرف على التحديات والمشكلات التي واجهتهم خلال انتشار فيروس كورونا (COVID-19)، والحلول المقترحة من وجهة نظرهم.

مشكلة الدراسـة:

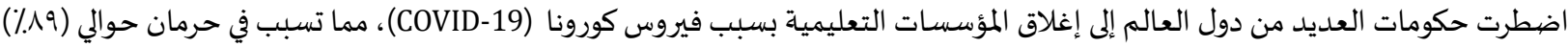

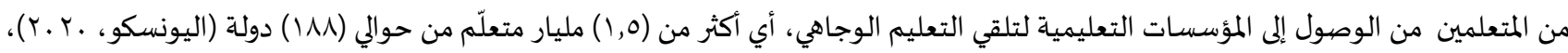

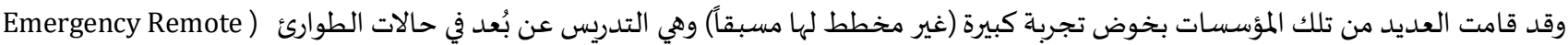

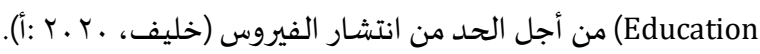


لقد أدى التحول المفاجئ للتدريس عن بُعد إلى صدمة وتوتر لدى كل من الطلبة، والمعلمين، والأهالي، بالإضافة إلى القادة ومتخذي القرار التربويين، لما تحتاجه العملية من جهود مختلفة وكبيرة للمضي قدماً في استمرارية العملية التربوية من جهة، وما يتطلب ذلك من بنى تحتية وتوفير

أجهزة تقنية وبيئة تعلّم مناسبة، بالإضافة إلى عدم جاهزية المحتوى الرقهي، وغير ذلك (Kyungmee, 2020 ; Saavedra, 2020)

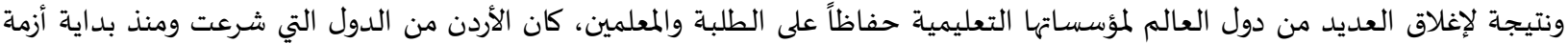
كورونا (COVID-19)، بوضع حلول بديلة للمحافظة على استمرارية تعلم الطلبة في بيوتهم. من خلال تفعيل العديد من منصيات التعلّم الإلكتروني مثل

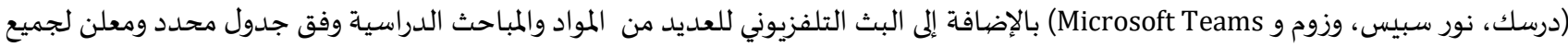
الطلبة في الأردن. مع التأكيد أن جميع هذه الخيارات قُدمت بالمجائان دون أن يدفع الطلبة أي مقابل مالي للدخول إليها والاستفادة من محتوياتها. وشجعت وزارة التربية والتعليم الأردنية المعلمين على استخدام مودام مواقع التواصل الاجتماعي التي تسهل عملية التواصل مع طلبتهم وتحقيق مخرجات

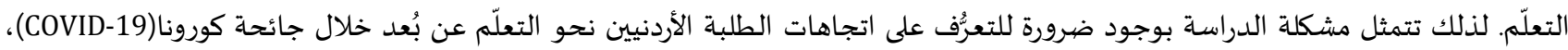

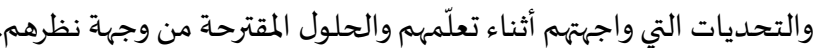

أسئلة الدراسـة:

تحاول الدراسة الإجابة عن الأسئلة التالية:

ا. ـ ما اتجاهات طلبة التعليم الأساسي والثانوي قي الأردن نحو التعلّم عن بُعد في ظل جائحة كورونا (COVID-19)؟

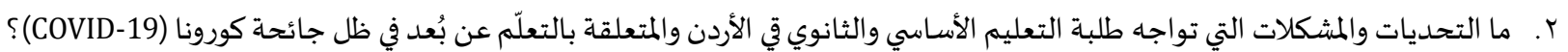

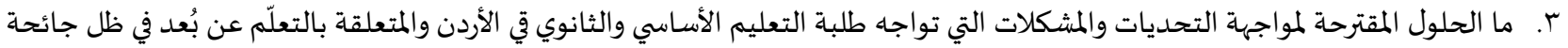

كورونا (COVID-19

أهداف الدراسـة:

تسعى الدراسة إلى تحقيق الأهد اف التالية:

ا. استكشـاف معدل اتجاهات الطلبة الأردنيين نحو التعلّم عن بُعد في ظل جائحة كورونا (COVID-19).

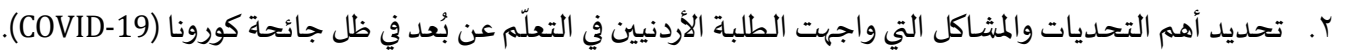

r. تقديم الحلول والاقتراحات من وجهة نظر الطلبة الأردنيين لمواجهة المشاكل والتحديات في التعلّم عن بُعد في ظل جائحة كورونا (COVID-19).

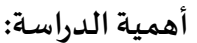

تكمن أهمية هذه الدراسة في كونها تتعلق بتوظيف التعليم الإلكتروني والتعلم عن بُعد خلال جائحة كورونا من خلال منصات التعليم والتعلم

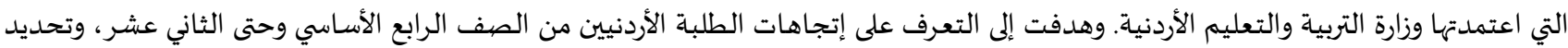
أهم التحديات والمشكلات التي واجهتهم خلال تعلمهم خلال إلكترونياً، ومقترحاتهم لتلافهيا من وجهة نظرهم. حيث يمكن للقائمين على تصميم المواد

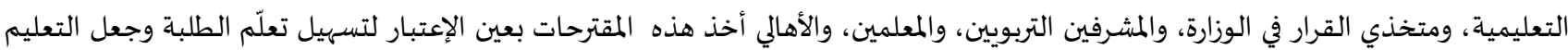
والتعلم الإلكتروني والتعلم عن بعد ثقافة معمول بها في الأردن حتى بعد انتهاء جائحة كورونا (COVID-19).

حدود الدراسـة:

تمثلت حدود الدراسـة في التالي:

ا. . اقتصرت هذه الدراسة على طلبة التعليم الأساسي والثانوي في الأردن خلال جائحة كورونا (COVID-19).

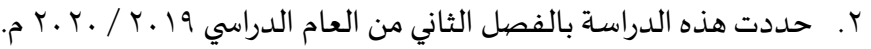

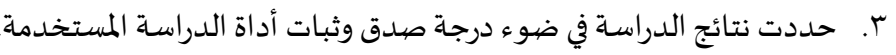

التعريفات الإجر ائية: التعلّم عن بُعد: هو النظام الذي اعتمدتها وزارة التربية والتعليم في ظل جائحة كورونا لتقديم محتوى جميع المباحث التعليمية للطلبة إلكترونياً عبر منصيات مختلفة مثل درسك، زوم، نور سبيس، وميكروسوفت تيمز، بالإضافة إلى المحطات التلفزيونية وتفعيل مواقع التواصل الاجتماعي.

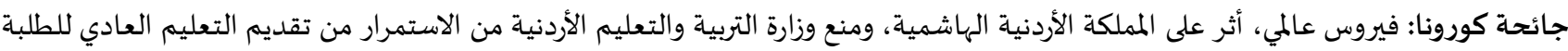

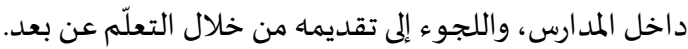

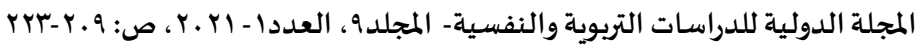


مشكلات التعلّم عن بُعد: المصادر (اللوجستية، أو المهارات التكنولوجية أو تصهيم المادة التعليمية أو إمكانية الوصهول للمنصيات التعليمية) التي تعيق أو تحد من تعلم الطلبة عن بُعد.

الإطار النظري:

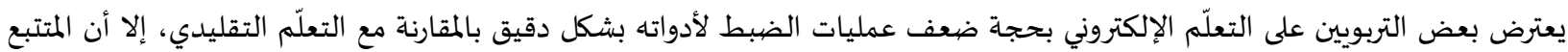

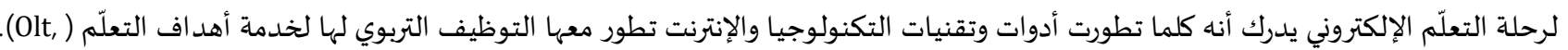
2018; Zhou, et. al., 2020

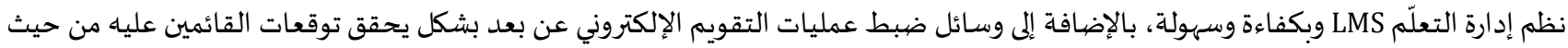

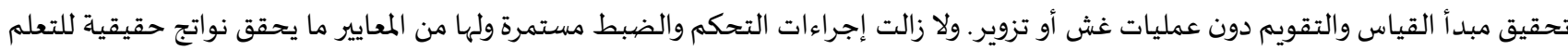
(Al-Shorman, \& Bawaneh, 2018)

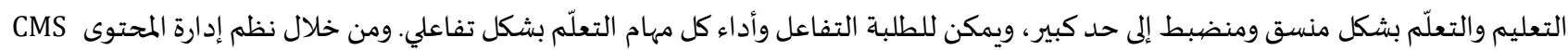
يمكن ترتيب وتنظيم المصادر التعليمية المتنوعة بشكل يمكن أن يساعد عضو هيئة التدريس في الجامعاة والمتعلم على تحقيق الأهداف التعليمية بشكل

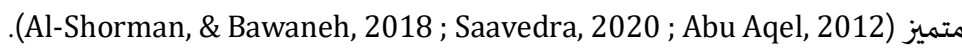
إن الخطوة السريعة في التدريس عن بعد في جائحة كورونا (COVID-19) جعلت المعلمين يتدافعون لمعرفة كيفية استخدام الأدوات الرقمية

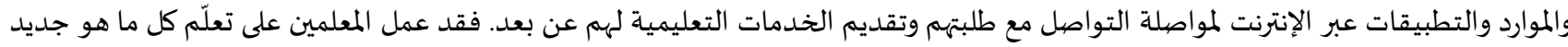

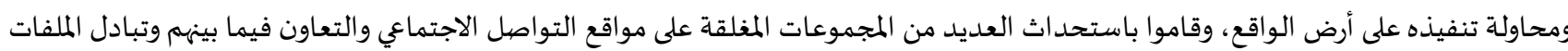

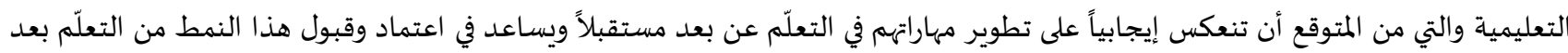

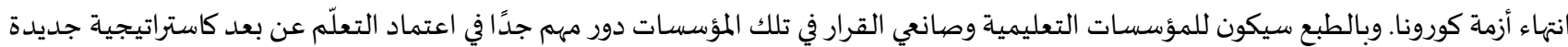
في العملية التّعليمية التعلّمية مستقبلاً (Mailizar, et. al., 2020; Sintema, 2020).

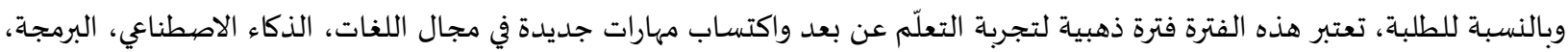

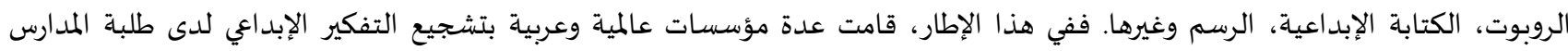

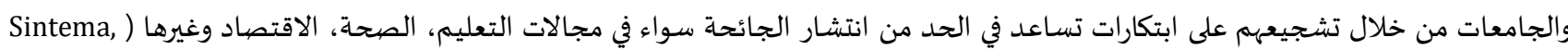

(2020

على الرغم من كل ما تم تطبيقه على أرض الواقع من ممارسات تعليم وتعلُّم إلكتروني، إلا أنّ ما تم تطبيقه في المدارس لا يمكن أن أن نصفهاه بالتعلّم

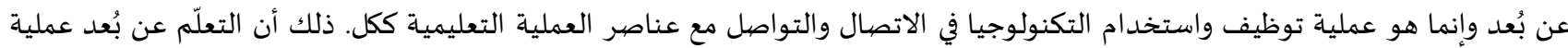

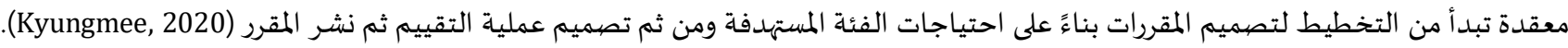

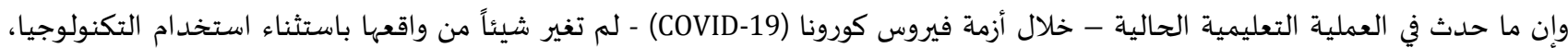

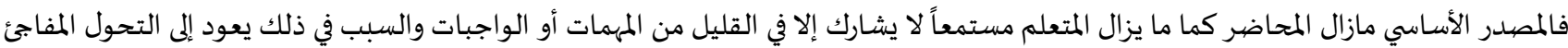

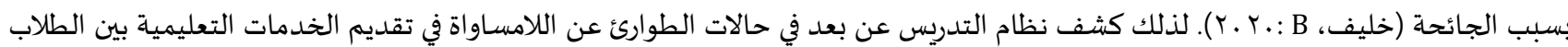

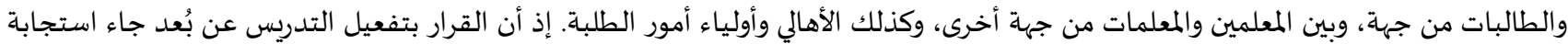

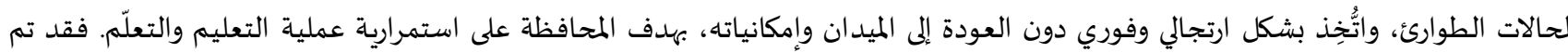
الانتقال إلى النظام الجديد خلال أقل من أربع وعشرين ساعة دون أي فترة انتقالية تجريبية أو بشكل تدريجي، ولم يتم التأكد من جاهزية المعلمين

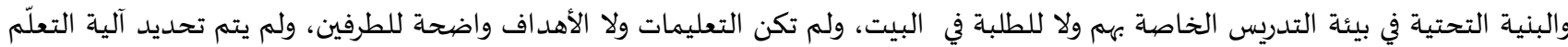

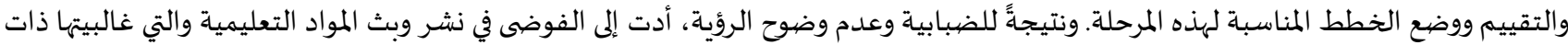

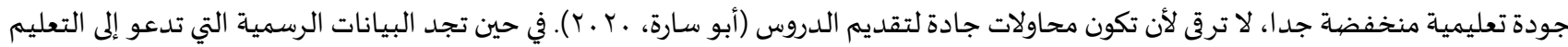

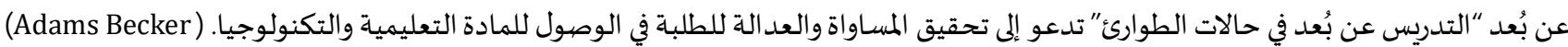

et al., 2018

دور المعلم و المتعلم في التعليم والتعلّم عن بُعد:

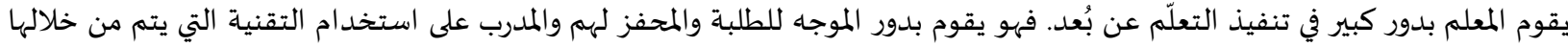

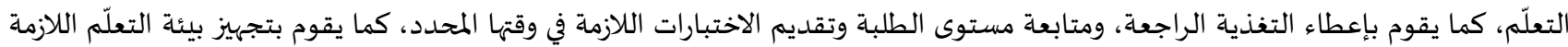

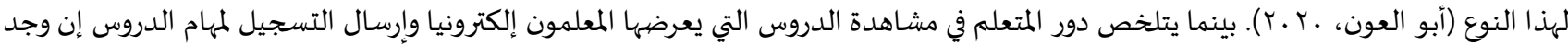


وكذلك العروض التقديمية والواجبات والأنشطة، ويقوم الطلبة بإعادة سماع ومشاهدة الدروس مرات عديدة وحل الواجبات وإرسالها إلكترونياً أيضاً،

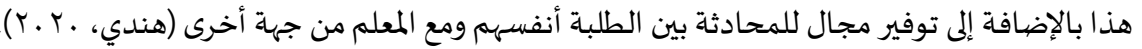

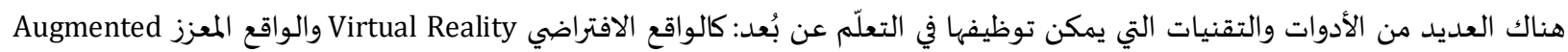
reality والواقع المختلط reality وبيئات التعلّم الافتراضية Virtual Learning Environment وبيئات التعلّم الشخصية PLEs ومنصات

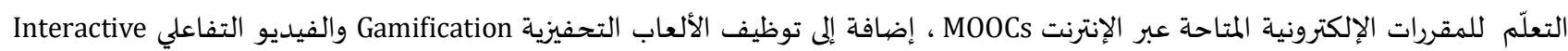
تVideo الذالإضافة إلى الذكاء الاصطناعي Artificial Intelligence الذينتظر أن يكون له دور كبير في المستقبل القريب وغيرها الكثير من مستحدثات

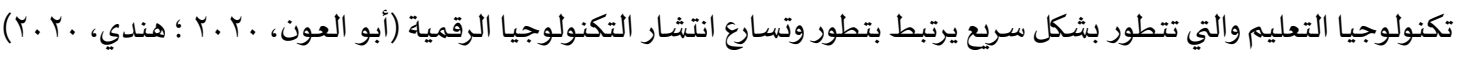

الدراسـات السابقة:

Ozgur Yilmaz, 2015; Miltiadou and Savenye, 2003; Olt, 2018; Zhou, et. al., 2020; Glenda ) أجريت العديد من الدراسات مثل (Kee, 2019 التي تخص موضوع الدراسة والتي اهتمت بدراسة أثر التعلّم عن بُعد والفصول الافتراضية المتزامنة أو غير المتزامنة على تحصيل

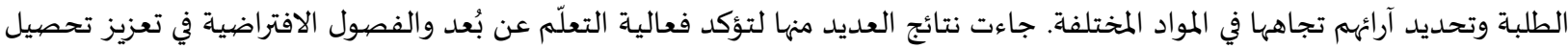

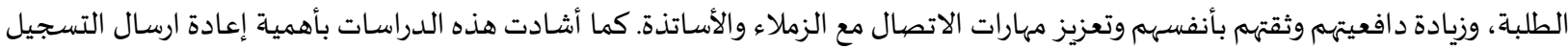
الخاص بالفصل الافتراضي المتزامن حيث يفسح المجال للطلبة بالرجوع إليه مرات عديدة في الوقت والمكان المناسب لهم، وهذا يزيد من فهم

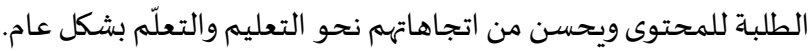

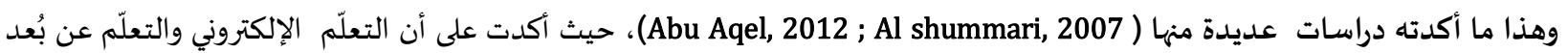
يحسن من تعلم الطلبة للمقررات، مع ظهور فروق ذات دلالة احصائية بين الذكور والإناث ولصالح الإناث. من جهة أخرى لم تتوصل دراسـة (2006) Ibn Fahed (لفعالية التعلّم الإلكتروني على تحسين اتجاهات الطلبة نحو التعلّم. ومؤخراً، قام (2018) Alakharas بدراسة أثر التعلّم عن بُعد على تحصيل الطلبة في مقرر الرياضيات مقارنة بالطريقة الاعتيادية، وأشارت

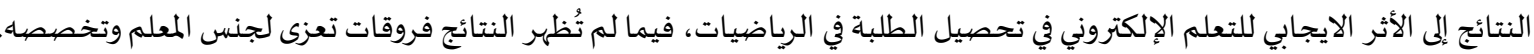

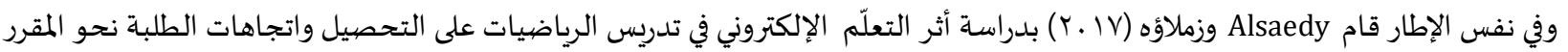
الدراسي في سلطنة عُمان، وجاءت نتائج هذه الدراسة متوافقة مع دراسة Alakharas وغيرها من الدراسات بالأثر الإيجابي للتعلم عن بُعد على تحصيل الطلبة وتعزيز اتجاهاتهم نحو المادة الدراسية.

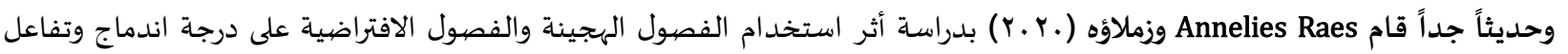
الطلبة وأدائهم. وعلى الرغم من أن الفصول الهجينة والافتراضية مبشرة بالخير وتدعم تحصيل الطلبة ذلك أهها تعطيهم مرونة وحرية في اختيار

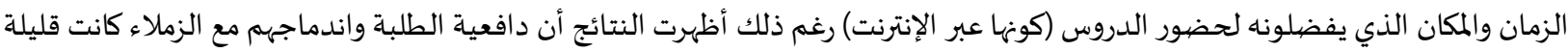

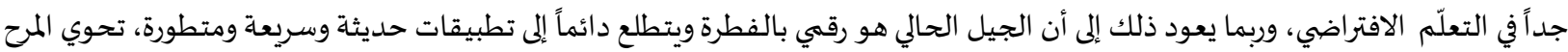

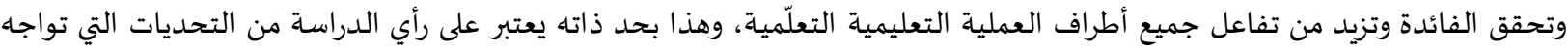
العملية التربوية. كما جاءت دراسة زهو وزملاءه (Zhou, et. al., 2020) لتؤكد على أهمية التعلم الإلكتروني والتعليم عن بعد واستخد ام الهاتف المحمول. وأعتبرت

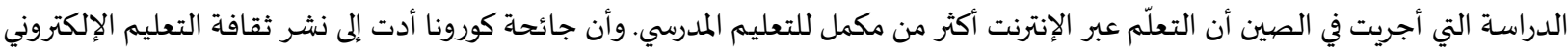

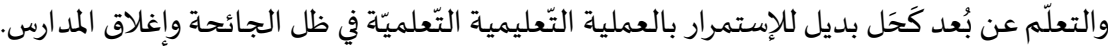
وفي دراسـة سنتيما (Sintema, 2020) التي هدفت إلى دراسة أثر جائحة فيروس كورونا على أداء طلبة الصف الثاني عشر من وجهة نظر معلمي

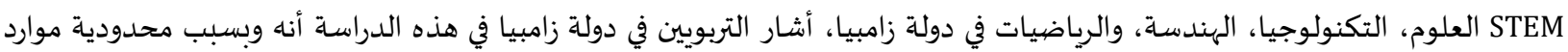
البلاد التكنولوجية وصعوبة المرحلة المتمثلة بتفشي فيروس كورونا والإغلاق المبكر والمفاجيء للمدارس إلى أحتمالية أن يكون هنالك انخفاض في

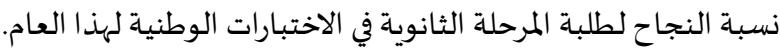
وبهدف دراسة متطلبات التعلّم عن بُعد ومعوقاته توصل الباحثين (Alshahrani, 2010) ; إلى أهميته على الرغم من كثرة الأعباء

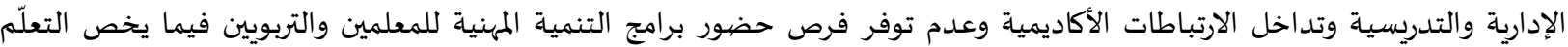

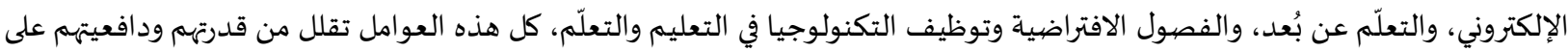
استخدام التكنولوجيا في التعليم والتعلّم. 
وفي دراسـة مايليزار (Mailizar, 2020) والتي هدفت إلى استطلاع وجهات نظر معلمي الرياضيات في اندونيسيا حول التحديات التي تواجه التعليم والتعلّم الإلكتروني أثناء جائحة كورونا، حيث حرمت هذه الجائحة أكثر من (0) مليون طالباً وطالبة وأكثر من (Y) مليون معلم من التعلّم

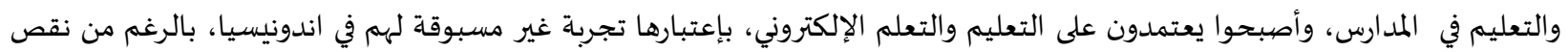

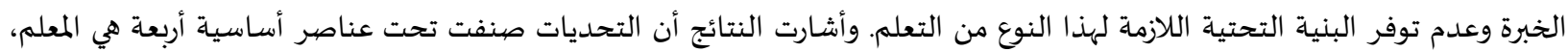

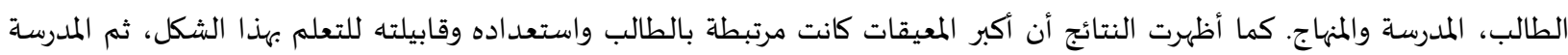
والمنهاج. فيما لم تظهر الدراسة معيقات حقيقية مرتبطة بالمعلم. وفي نفس السياق جاءت دراسة (Tami , 2016) لتؤكد على أهمية التعلّم عن بُعد والتعلّم الافتراضي وأنه من مظاهر التقدم العلمي

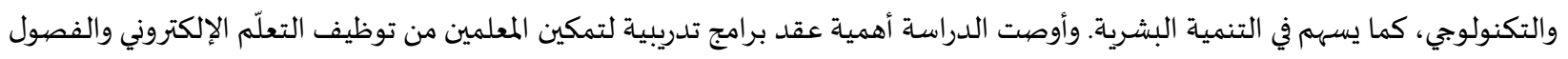
الافتراضية وأدواتها لتعزيز التعليم والتعلّم. تعقيب على الدراسـات السـابقة:

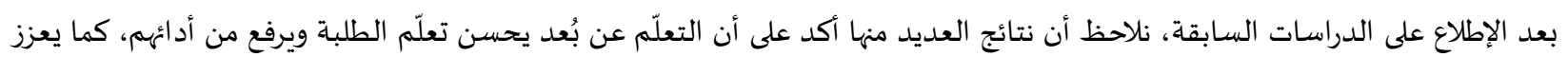

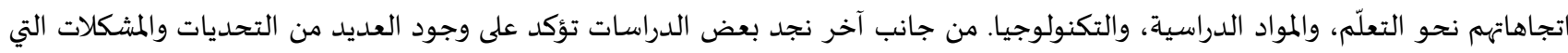

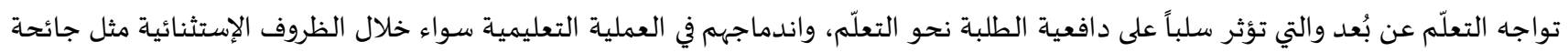

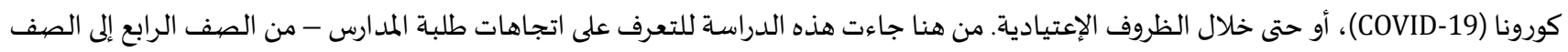

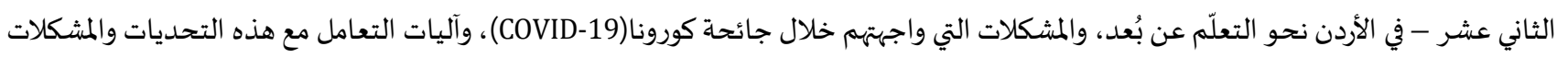
لحلها من وجهة نظر الطلبة.

الطريقة والإجراءات:

اعتمدت الدراسة المنهج الوصفي التحليلي لنوعين من البيانات التي تم جمعها من عينة الدراسة وهي: بيانات كمية من خلال الجزء الأول من

استبيان الدراسة (ليكرت سداسي)، وبيانات نوعياة تمثلت في الأسئلة المفتوحة في الجزء الثاني من الاستبيان.

\section{مجتمع الدراسـة وعينتها:}

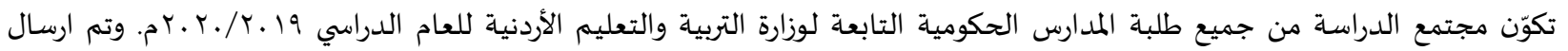

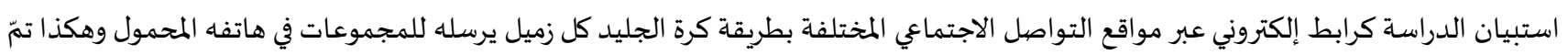
ارسالها للطلبة في جميع مناطق المملكاة، حيث استهدفت الدراسة الطلبة الذكور والإناث لجميع المراحل المدرسية (الثانوية، الأساسية العليا، والأساسية

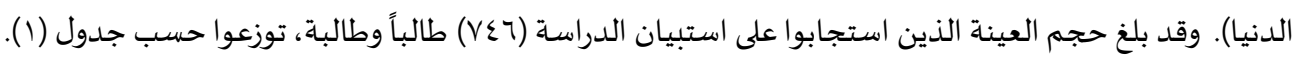

جدول (1): وصف عينة الدراسة وفقا للمتغيرات الديمغر افية (الجنس، الإقليم الذي يسكنه الطالب ، المرحلة الدراسية)

\begin{tabular}{|c|c|c|c|}
\hline النسبة \% & 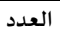 & \multicolumn{2}{|c|}{ المتغير } \\
\hline$\%$ & 101 & ذكر & \multirow[t]{3}{*}{ الجنس } \\
\hline \%/va & 091 & انثى & \\
\hline$\%$ \%. & $V \varepsilon 7$ & مجموع (مجو & \\
\hline \% $\mathrm{TV}$ & $r .$. & جنوب & \multirow[t]{4}{*}{ الاقليم الذي يسكنه الطالب } \\
\hline$\%$.0 & $\varepsilon \cdot V$ & وسط & \\
\hline$\% 19$ & $1 \leqslant 1$ & 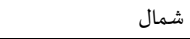 & \\
\hline$\%$ & $V \leqslant 7$ & مجموع | (مجوع & \\
\hline$\%$ \% & rM & الثانوية (1/ 1 1 ) & \multirow[t]{4}{*}{ المرحلة الدراسية } \\
\hline$\% \varepsilon$ & ror & الأساسية العليا (1-.. () & \\
\hline \% & WI & الاساسية الدنيا (§-V) & \\
\hline$\%$ & $v \varepsilon \eta$ & مجموع & \\
\hline
\end{tabular}

يلاحظ من الجدول (1) أن عينة الدراسة شملت (7ع V) طالباً وطالبة موزعين في ثلاثة متغيرات. وقد شملت العينة(101) طالباً و (109) طالبة.

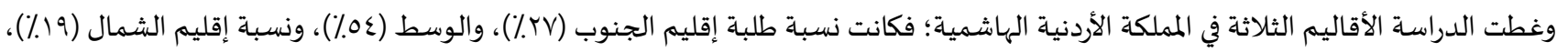

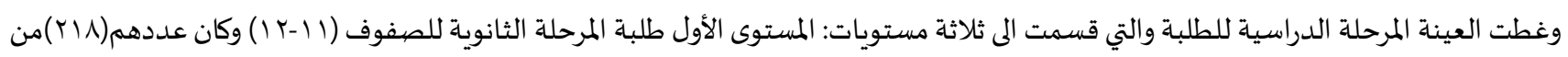

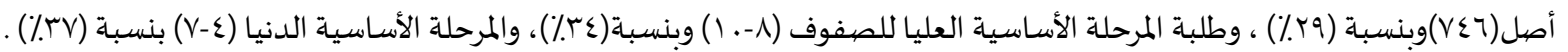


Ozgur Yilmaz, 2015; ) قام الباحثان بالاطلاع على الأدب النظري والدراسات السابقة المرتبطة بالتعليم والتعلّم الإلكتروني والتعلّم عن بُعد Miltiadou and Savenye, 2003; Olt, 2018; Al-Shorman, and Bawaneh, 2018

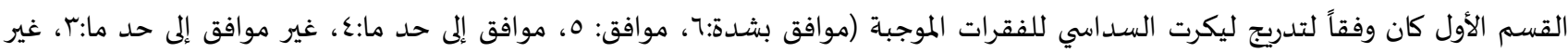
موافق:؟، غير موافق إطلاقاً:()، والعكس تماماً في توزيع الدرجات للفقرات السالبة، وقُسم الجزء الأول من الأداة إلى محورين: الأول هدف إلى قياس

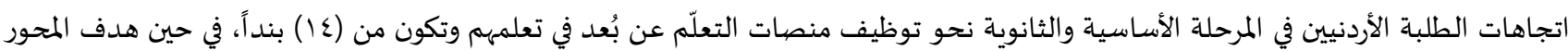

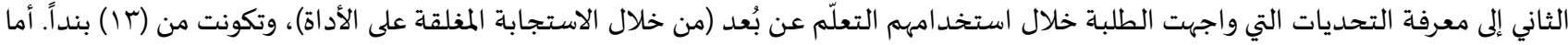

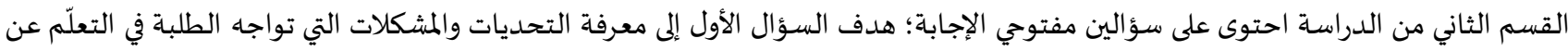

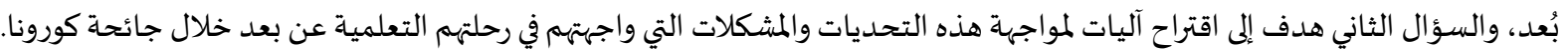
صيدق الأداة:

للتأكد من صيدق أداة الدراسة، تم عرض النسخة الأولية منها والتي تكونت من (Y9) فقرة على مجموعة من المحكمين شملت أعضياء هيئة تدريس

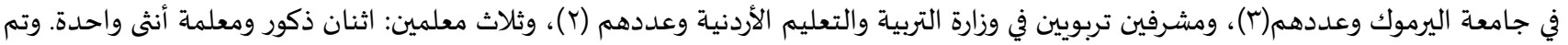

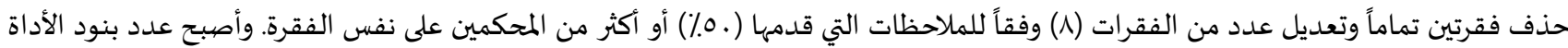
بصورتها النهائية (YV) بنداً، منها (ع () بنداً تمثل الاتجاهات، و(r) (I) بنداً تمثل التحديات والمشكلات، وكذلك تمت الموافقة من المحكمين على الأسئلة مفتوحة النهاية مع تعديل بسيط في صياغة السؤال الثاني. ثبات الأداة:

لحساب ثبات أداة الدراسة قام الباحثان بإتباع طريقة الإختبار وإعادة الإختبار (Test - Retest) بفارق زمني مقداره أسبوعان، وقد تم تطبيق الأداة على عينة من مجتمع الدراسة تم استثنائها من عينتها وقد بلغ معامل الثبات للقسم الأول للأداة (19 (.).)، حيث تعتبر هذه القيمة من الثبات مناسبة - ممتازة - للتطبيق الفعلي (Al-Kellani and Al-Shraifeen, 2011 ; Obiedat, Kayed, and Adass, 2016). مئك مئه

نتائج الدراسـة ومناقشتها: الإجابة عن سؤال الدراسـة الأول والذي ينص على "ما اتجاهات طلبة التعليم الأساسي والثانوي في الأردن نحو التعلّم عن بُعد في ظل جائحة كورونا (COVID-19) للإجابة عن السؤال قام الباحثان بحسـاب المتوسط الحسابي والانحراف المعياري والنسبة المئوية لبنود الأداة المعدة لهذه الغاية، وكانت النتائج كما في جدول (Y)، علماً بأنه تم تصنيف رتبة الفقرات وفقاً للمعادلة التالية (Al-Rashidi, 2018 ; Bawaneh, \& Moumene, 2020):

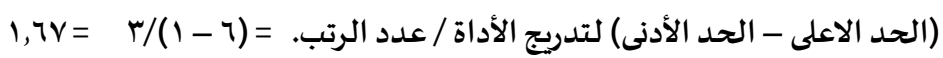

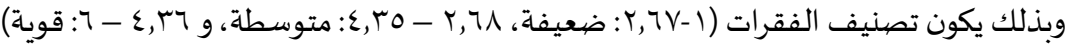
جدول (r): المتوسطات الحسابية والانحر افات المعيارية والنسب المئوية لاتجاهات الطلبة قي الأردن نحو التعلّم عن بُعد

\begin{tabular}{|c|c|c|c|c|c|}
\hline 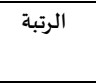 & 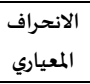 & النسبة المئوية & المتوسط المبط & 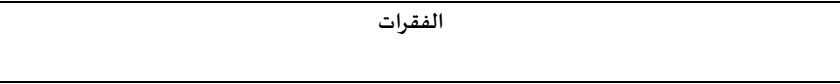 & 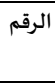 \\
\hline قوية & 1,77 & IVT & $\varepsilon, r \wedge$ & أفضضل أن يصبح التعلّم عن بُعد هو الوضع المعتاد للتعلم. & 1 \\
\hline متوسطة & $1, \mathrm{v1}$ & $\% / 70$ & $r, 91$ & مروس التعلّم عن بُعد توفر لي المزيد من الوقت والجهد. & $r$ \\
\hline 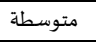 & 1,70 & $\% / 79$ & $\varepsilon, 17$ & أشعر بالمتعة من خلال التعلّم عن بُعد. & $r$ \\
\hline متوسطة & 1,79 & $\% / 11$ & $\varepsilon, .7$ & أعتقد أن التعلّم عن بُعد يمنحني ثقة أكبر في النفس. & $\varepsilon$ \\
\hline متوسطة & l,v. & $1 / 79$ & $\varepsilon, 19$ & لم التعلمّم عن بُعد زاد من دافعيتي نحو التعلَمه. & - \\
\hline متوسطة & $1,7 \pi$ & $\%$. & $r, 9 \mathrm{~V}$ & أعتقد أن التعلّم عن بُعد يحد من حرية التفكير لدي. & 7 \\
\hline 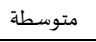 & 1,77 & $\%$ \% & $r, 10$ & لا أشعر بالارتياح عندما أُكلّف بعمل/واجب من خلال التعلّم عن بُعد. & $\mathrm{r}$ \\
\hline ضيفية & 1,79 & $\%$ \%) & $r, \varepsilon V$ & أُفضِّل استخدام وسائل وطرق التعلَم الاعتيادية على التعلّم عن بُعد. & $\wedge$ \\
\hline ضيفة & 1,07 & $\%$ & r,r. & لا أثق بالتعلَم عن بُعد من ناحية صدق تقييم أدائي ومستواي الأكاديمي. & 9 \\
\hline متوسطة & 1,71 & $\% / 71$ & $r, 71$ & التعاوني، حل المشكلمات). & 1. \\
\hline قوية & 1,7 & $\% \mathrm{YA}$ & $\varepsilon, 77$ & التعلّم عن بُعد شجعني على التعلّم الذاتي. & 11 \\
\hline 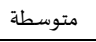 & $1,7 \mathrm{~V}$ & $\% 71$ & $r, 70$ & استخدام التعلّم عن بُعد سهل عليَ الاستزادة من المملومات والوصول لها من المواقع المختلفة. & ir \\
\hline متوسطة & $1, \mathrm{VV}$ & $\%$ & $r, \imath$. & يسعدني أن المدرس يستخدم أكثر من طريقة وأسلوب في طرح المادة باستخدام التعلّم عن بُعد. & ir \\
\hline متوسطة & $1, \mathrm{~V}$, & $\% 07$ & $r, r \Lambda$ & لـه. & I\& \\
\hline متوسط & $1,7 \mathrm{~V}$ & $\%$ & $r, 09$ & المتوسط العام & \\
\hline
\end{tabular}




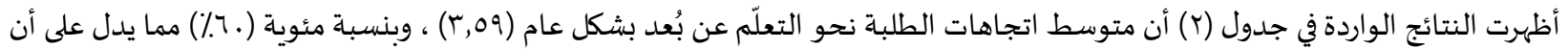

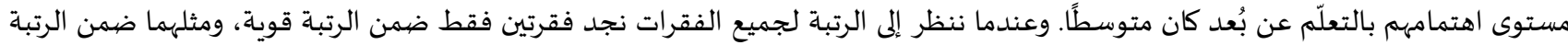

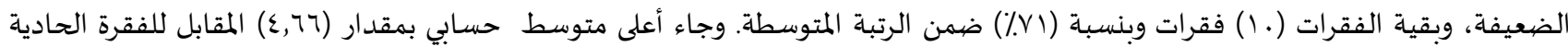
عشرة، مما يشير إلى أن استخدام التعلّم عن بُعد ساهم في تشجيع الطلبة وساعدهم على أن يكونوا متعلمين مستقلين في تنفيذ معظم المهام والأنشطة

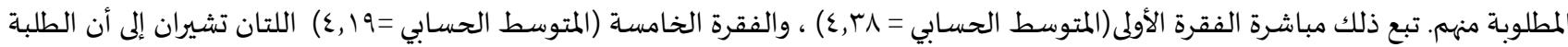
يفضلون التعلّم عن بُعد ليصبح الوضع المعتاد للتعلم في الظروف الاعتيادية لأنه يزيد من دافعيتهم نحو التعلّم. ثم تشير الفقرتان الثالثة والرابعة

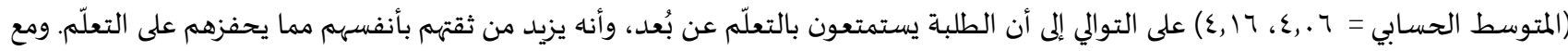

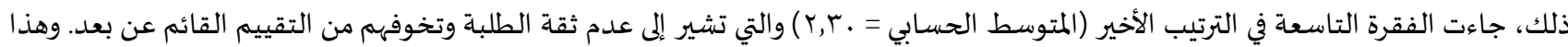

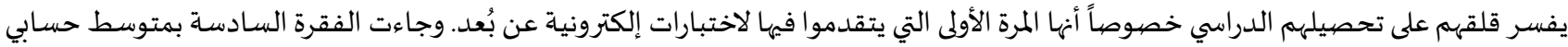

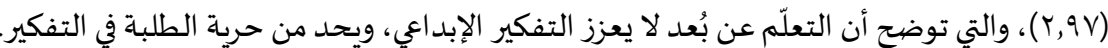
الإجابة عن سؤال الدراسـة الثاني والذي ينص على "ما التحديات والمشكلات التي تواجه طلبة التعات التعليم الأساسي والثانوي في الأردن والمتعلقة بالتعلّم عن بُعد في ظل جائحة كورونا

اعتمد الباحثان في الإجابة عن هذا السؤال على مصديدين، الأول على بنود المحور الثاني من الاستبانة (الاستجابة المغلقة)، والمصددر الثاني، إجابة

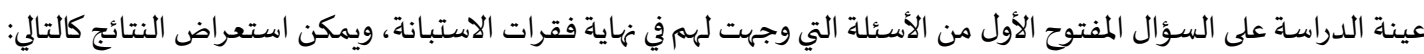

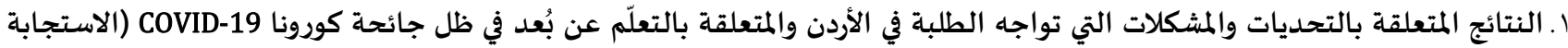

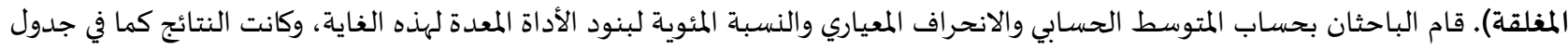

جدول (r): المتوسطات الحسابية والانحر افات المعيارية والنسب المئوية للتحديات والمشكلات التي تواجه الطلبة نحو التعلّم عن بُعد

\begin{tabular}{|c|c|c|c|c|c|}
\hline الرتبة & المعياري & المئوية & المستوسطي & التحديات والمشكلات التي تواجه الطلبة في التعلم عن بعد & الرقم \\
\hline ضعيفة & $1, \varepsilon V$ & $\%$ \%. & $r, \varepsilon 1$ & التعلَم عن بُعد لا يراعي تصميم أنشطة وفعاليات تراعي الفروق الفردية بيننا كطلبة. & .1 \\
\hline ضيفة & $1, \varepsilon \vee$ & Trt & 1,9 . & 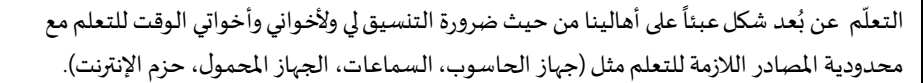 &.$r$ \\
\hline ضعيفة & $1, r \Lambda$ & $\%$ & $r, r$. & التعلّم عن بُعد يضعف الترابط الاجتماعي بيني وبين زملائي الطلبة. &.$r$ \\
\hline ضيفيفة & $1, r 1$ & $\%$ & 1,17 & بطئ سرعة الإنترنت يستهلك كثيرا من وقتي مما يتسبب في تقليل دافعيتي نحو التعلَم عن بُعد. &.$\varepsilon$ \\
\hline ضعيفة & $1, r 9$ & /rt & 1,91 & كثرة انقطاع الاتصال أثناء التواصل المباشر مع المعلم وزملائي يشعرني بالملل بالتعلّم عن بُعد. & .0 \\
\hline ضعيفة & 1,0r & $\% \mathrm{rv}$ & $r, r$. & | تكلفة الإشتراك بالإنترنت يحد من قدرتي على المشاركة بالتعلّم عن بُعد. & .7 \\
\hline ضعيفة & 1,01 & $\%$ \%. & $r, \varepsilon 1$ & أواجه صعوبة في الوصول للمهمات والمصادر والقراءات التي يقوم المدرس بارسالها لي في التعلّم عن بُعد. &.$v$ \\
\hline ضعيفة & 1,01 & $\%$ & r, ro & ق قد ألتهي ببعض الاعلانات و المواقع والروابط أثناء التعلّم عن بُعد. & .1 \\
\hline ضعيفة & 1,49 & \% & 1,97 & لا أشعر أنه يوجد تفاعل وتواصل بيني وبين المملم في التعلّم عن بُعد كما هو الحال في الصفوف الاعتيادية. & .9 \\
\hline ضيفيفة & $1, v_{0}$ & $\%$ & $r, £ 0$ & | أواجه صعوبة في استخدام الجهاز المحمول في التعلّم عن بُعد لعدم توفر جهاز كمبيوتر لدي . & .1. \\
\hline ضيفية & $1, \pi$ & /rt & 1,91 & بعض المواد الدراسية تحتاج منا أن نطبق بشكل عملي وهذا لم يوفره لنا بيئة التعلَم عن بُعد. & .11 \\
\hline ضعيفة & $1, r \Lambda$ & $\%$ & r,1. & لا أحصل على تغذية راجعة مفيدة وكافية على إجاباتي ومشاركاتي من خلال التعلّم عن بُعد. & $.1 r$ \\
\hline ضعيفة & $1, \varepsilon \wedge$ & $\%$ & $r, r)$ & | أحتاج لبرامج تدريبية تساعدني على استخدام أنظمة التعلّم عن بُعد بكفاءة. & $.1 \%$ \\
\hline ضيف & $1, £ 0$ & \% & $r, 1 \varepsilon$ & المتوسط العام & \\
\hline
\end{tabular}

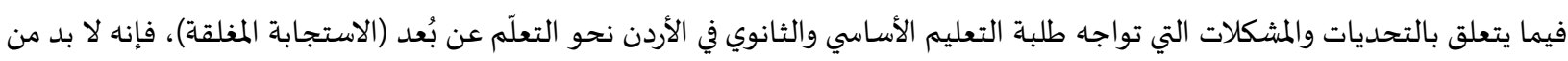

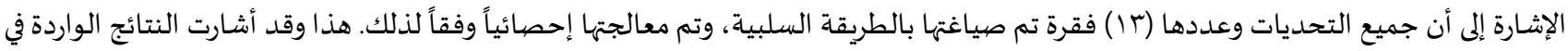

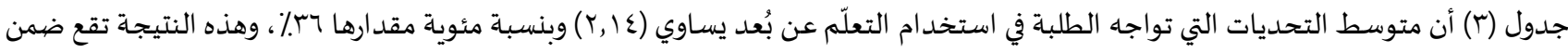
الفئة الضعيفة، مما يدل على أن مستوى التحديات التي يواجهونها في التعلّم عن بُعد كانت كثيرة ومتعددة ـ وعندما ننظر إلى رتبة تصنيف التهات التحديات نجد أن جميع التحديات ضعيفة وتشكل تحديات ومشاكل حقيقية في تعلّم الطلبة.

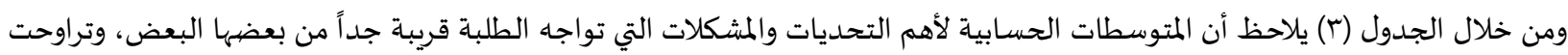

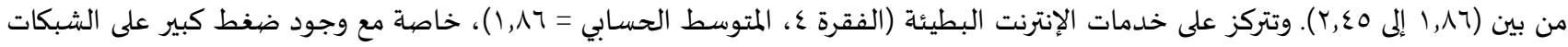

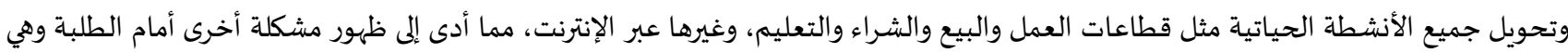

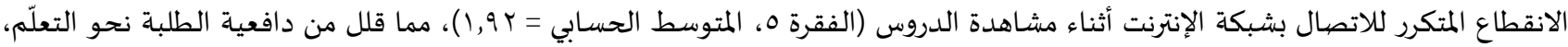
وجعل التعلّم غير مثير للاهتمام بالنسبة لهم وهذا اتجاه سلبي. من ناحية أخرى، أدى هذا النوع من التعلّم إلى زيادة العبـ العبـ على الآباء من حيث تكلفة 
الإنترنت (الفقرة ؟، المتوسط الحسابي = . 9,1)، والافتقار لأجهزة الكمبيوتر، خاصة للأسر التي لديها العديد من الأبناء في المدراس ولديهم دروس

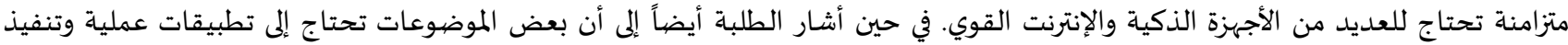

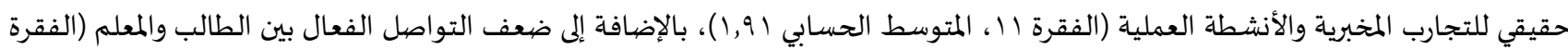
9، المتوسط الحسابي = 97, (1). وعدم حصول الطلبة على تغذية راجعة فعّالة وملاحظات كافية وبناءة بشأن واجباتهم المنزلية ومهامهم وتحقيقها لمعايير

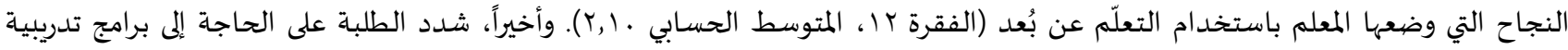
تساعدهم في كيفية استخدام أدوات التعلّم عن بُعد بحيث يكونون قادرين على التعامل مع منصات وبيئة التعلم الافتراضية بشكل أكثر فاعلية وإتقان

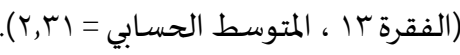

r. النتائج المتعلقة بالتحديات والمشكلات التي تواجه الطلبة قي الأردن والمتعلقة بالتعلّم عن بُعد في ظل جائحة كورونا COVID-19 (إجابة السؤال المفتوح) قام الباحثان بإجراء تحليل نوعي لجميع استجابات الطلبة على السؤال المفتوح الأول في أداة الدراسة، وخلصت النتائج إلى أن

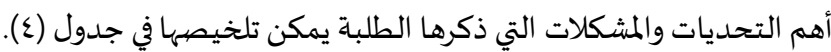

جدول (ع): التحديات والمشكلات التي تواجه الطلبة في التعلّم عن بُعد والنسبة المئوية لها

\begin{tabular}{|c|c|c|}
\hline النسبة المئوية النسبة & المشكلة أو التحدي الذي واجه الطلبة في التعلّم عن بُعد & 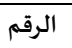 \\
\hline \%.A. & قلة التواصل وانعدام المشاركة الفعالة بين الطلبة والمعلمين وبين الطلبة أنفسهم. & .1 \\
\hline$\%$ & غموض آليات التقييم وطبيعة الاختبارات وانعدام التغذية الراجعة من المعلم للطلبة. &. \\
\hline$\%$ \%. & خدمات الإنترنت (السرعة قليلة جداً، الانقطاع المتكرر، عدم توفر الإنترنت ..). &.$r$ \\
\hline$\%$ \%. & الكلفة المادية على الأسر المتمثلة بتوفير بيئة مناسبة وشراء أجهزة وحزم إنترنت إضافية لحضور فعاليات التعلّم عن بُعد. &.$\varepsilon$ \\
\hline$\%$ & تصميم الدروس، فهي لا تتوافق مع نمط التعليم والتعلّم عن بُعد، بالإضافة إلى زيادة الواجبات على الطلبة. & .0 \\
\hline$\% \mathrm{VV}$ & فرقط. التدريس الإعتيادية التي يستخدمها المملمون في التعليم عن بُعد، فهي لم تراع تنوع الطلبة، وفي بعض الأحيان يلجأ المعلمون للقراءة & .7 \\
\hline$\%$ \%乏 & نقص تدريب الطلبة مسبقاً على كيفية استخدام منصات التعلّم عن بُعد. &.$v$ \\
\hline$\% \mathrm{TV}$ & 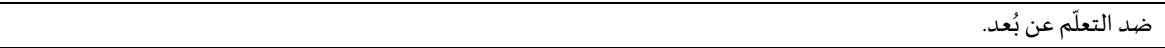 &.$\wedge$ \\
\hline$\%$ & لا يوجد مشاكل تذكر. & .9 \\
\hline
\end{tabular}

يبين جدول (ع) تصنيف لمعظم التحديات والمشكلات التي طرحها الطلبة. حيث نجد أن أبرزها ترتبط بخدمات الاتصال بالإنترنت حيث أشار

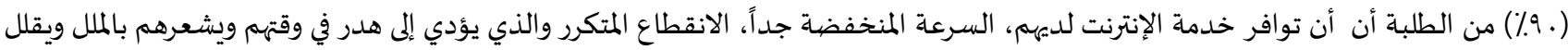

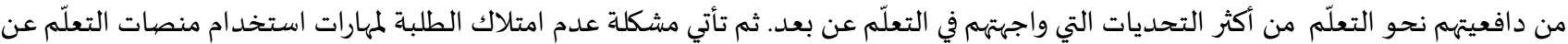

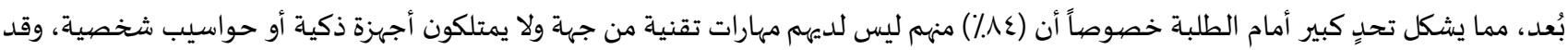
نعزو ذلك للتوظيف المفاجئ لهذا النوع من التعليم والتعلّم بسبب جائحة كورونا. والتحدي الثالث الأعلى كان المرتبط بصعوبة التواصل والمشاركة

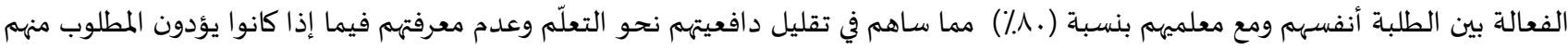

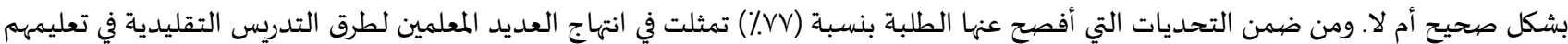
عن بُعد وعدم إعادة تصميم التدريس بطريقة تتناسب مع بيئة التعلّم عن بعد. فلم يتم الأخذ بعين الاعتبار تصميم معظم المقررات الدراسية وفقاً

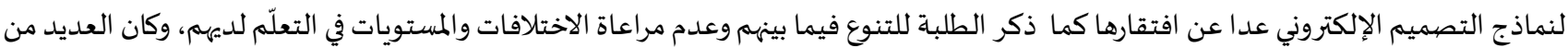
المعلمين يلجأون للقراءة فقط عبر المنصة الإلكترونية دون شرح مبسط أو عميق. كما يتضح من الجدول (ع) أيضاً أن التكلفة المادية للحصول على

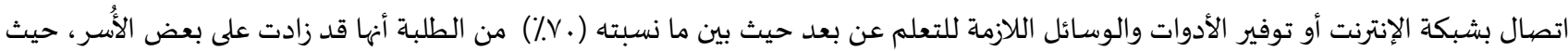
اضطرت هذه الأسر في هذا الظرف لدفع مبالغ مالية إضافية لشراء حزم كبيرة للإنترنت وبعض الادوات الأسر اضطرت لشراء أجهزة حواسيب مكتبية أو مأو

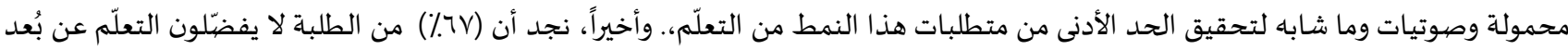
ويرغبون بالعودة للتعلّم المباشر (وجها لوجه) في المدرسة حيث بيّنت نفس النسبة من عينة الدراسة عدم ارتياحها مع تصهميم الدروس الذي تم من قبل

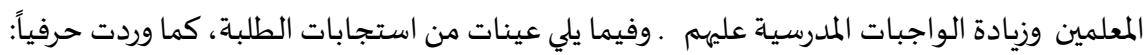
"عدم وجود جهاز للتعلم،ضعف في الإنترنت ،صعوبه فهم المواد عبء على الاهالي عدم قدره التواصل بيني وبين المعلم"

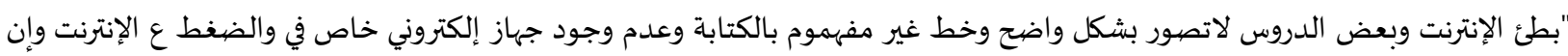

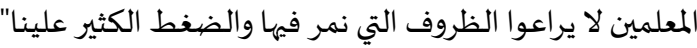

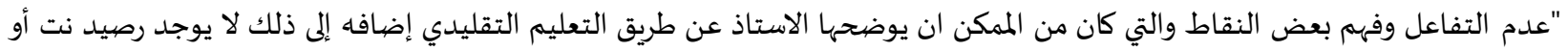

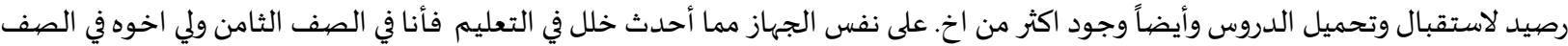

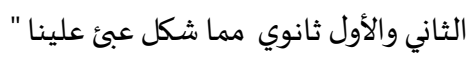


"تكلفة النت وصعوبة النقل من الهاتف والاعتماد على امي مثيرا في حل الواجبات لعدم فهمي الشرح من خلال التلفاز والهاتف"

"الضغط الكبير علينا كطلاب"

"ما بنفهم أبداً على الأساتذة وماشيين همة بسرعة كبيرة وتلفزيون بسرعة بشرحو وما بلحق نكتب معهم وانا وخواني لصغنار ما بنقدر كلنا ندرس

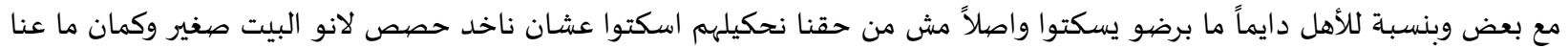

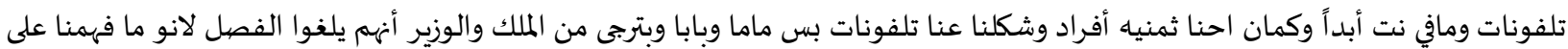

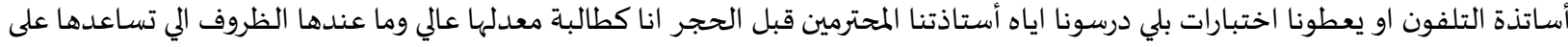

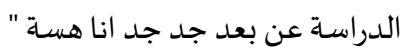

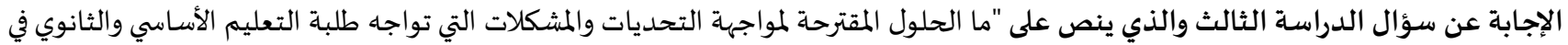

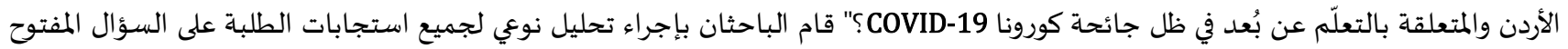

الثاني في أداة الدراسة، وخلصت النتائج إلى أهم الحلول المقترحة والتوصيات التي ذكرها الطلبة كما هو موضح في جدول (0).

جدول (0): الحلول المقترحة لمواجهة التحديات والمشكلات التي تواجه طلبة التعليم الأساسي والثانوي في الأردن المتعلقة بالتعلّم عن بُعد

\begin{tabular}{|c|c|c|}
\hline النسبة المئوية النسية & الحلول والتوصيات التي قدمها الطلبة في التعلّم عن بُعد & 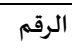 \\
\hline$\% \varepsilon$ & تنوريحة المصادر التعليمية وجعل الدروس عن بعد أكثر فاعلية (التعلّم باللعب، مسابقات، الغاز ...، وتصميم منصية أو تطبيق لكل & .1 \\
\hline$\%$ & تنظيم الوقت والدروس مثل إعداد جدول للدروس كما هو في التعليم الاعتيادي بالمدراس. & r \\
\hline$\% \mathrm{VV}$ & إعادة تصميم المحتوى العلمي ليتوافق مع التنوع في الطلبة والاختلافات في القدرات. & r.r \\
\hline$\%$ \% & تصميم آليات واضحة للتقييم بطرق مختلفة وتقديم التغذية الراجعة من المعلم للطلبة. &.$\varepsilon$ \\
\hline$\%$ & ربط التعلّم عن بُعد مع التعلّم المباشر (وجها لوجه) بشكل مناسب (التعليم المزجي- التوليفي). & .0 \\
\hline$\%$ r & توفير أجهزة الكترونية (لاب توبات، تابليت ...) للطلبة. & .7 \\
\hline$\% \mathrm{~V}$ & توفير بيئة تعلم تفاعلية واتصال مباشر مع المعلمين والزملاء الطلبة. &.$v$ \\
\hline$\%$ \% & اختيار أفضل المعلمين (المتميزين) في تقديم الدروس كحصص نموذجية. &.$\wedge$ \\
\hline$\%$ & توفير الإنترنت بسرعات مناسبة وحزم مفتوحة ومجانية للجميع. & .9 \\
\hline I.AT & تدريب الجميع (معلمين وطلبة) على كيفية استخدام منصات التعلّم عن بُعد. & 1. \\
\hline
\end{tabular}

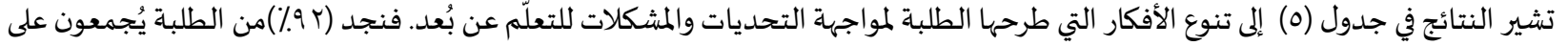
ضرورة توفير خدمات الإنترنت وبسرعات جيدة ومناسبة ومفتوحة الحزم بشكل مجاني لجميع الطلبة وهذا المقترح يحل المشكلة المرتبطة بالإنترنت التي

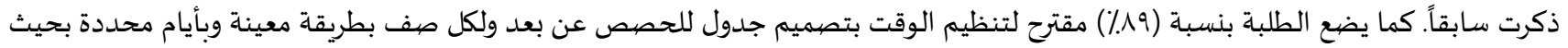

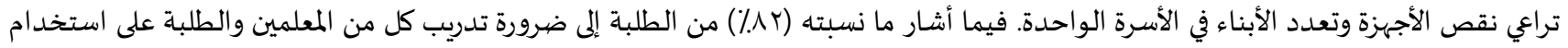

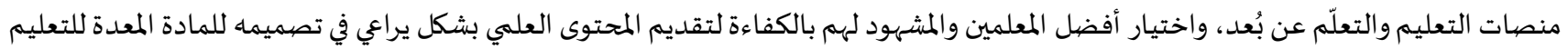

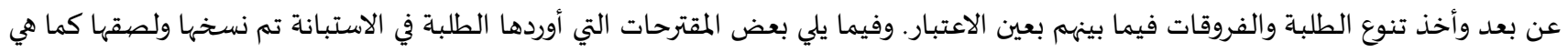
دون تعديل أو تغيير.

"دورات تدريبياء مكثفه للمعلمين والطلبه للتعلم عن بعد.. تحسين خدمة الإنترنت. توفير أجهزه اللابتوب للفئه المستهدفه"

"انتقاء معلمين جيدين من ذوات الخبرة المؤهلين حقا لتدريس طلاب ثانوية عامة"

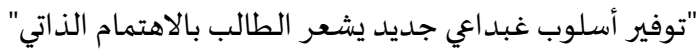

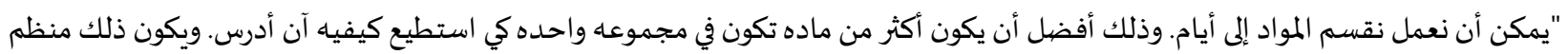
مع الوقت".

• "أن يكون التعلّم في وقت واحد للطلاب ومناسب الكل وأن يكرروا التوضيح للدرس أكثر من مره لأنه في طلاب بدهم توضيح اكثر"

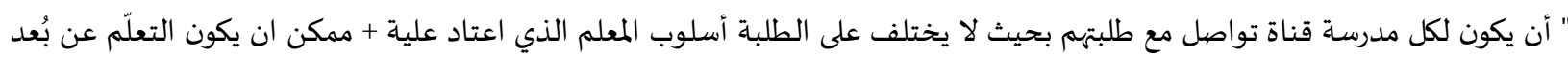

• " تنظيم وقت المعلم ومراعاة الفروقات بين مستويات الطلبة الذين يتابعوا التعليم عن بعد من خلال طرح الأمثلة واستخدام أكثر من طريقة

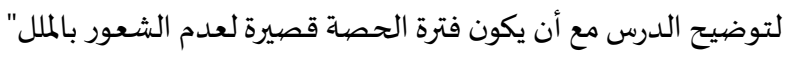

" توزيع أجهزة إكترونية مثل اللاب توب، مما يُسهل علينا التنقل من وإلى المواقع التعليمية، إضافة إلى إقامة حصص أونافيلاين للتغذية الراجعة" 
مناقشة النتائج:

جاء متوسط اتجاهات الطلبة الأردنيين بالتعلّم عن بُعد (متوسطة). وتعتبر هذه النتيجة طبيعية، فقد بدأت وزارة التربية والتعليم بتطبيق

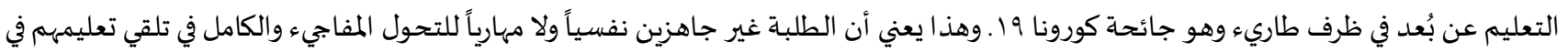

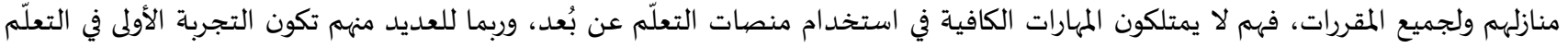

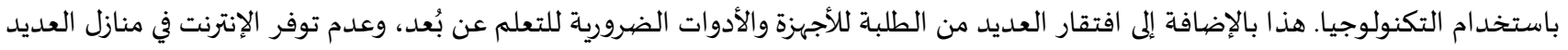

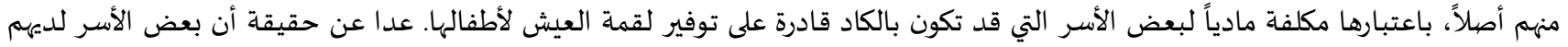

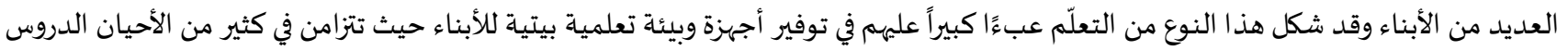

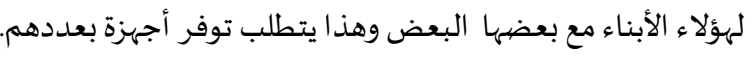

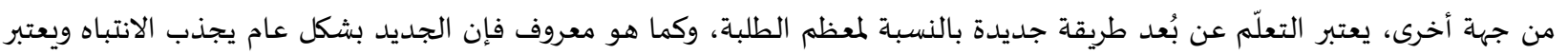

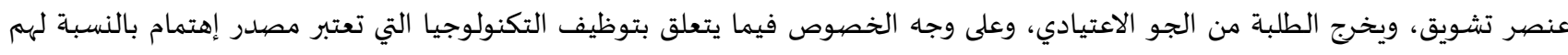

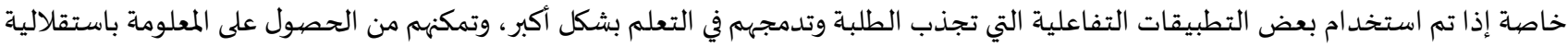

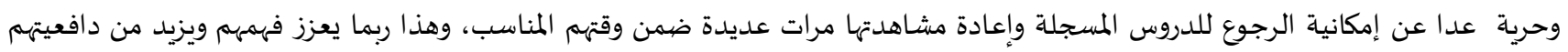

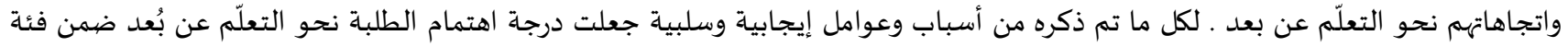

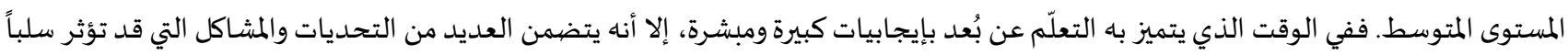
على تعلم الطلبة.

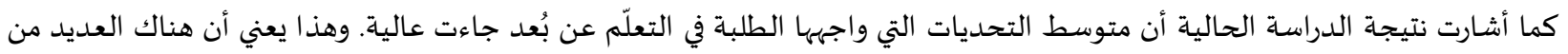

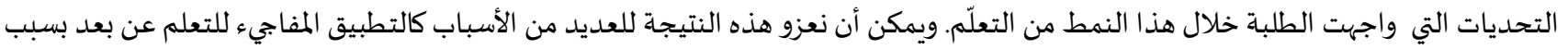

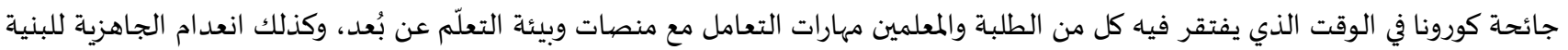

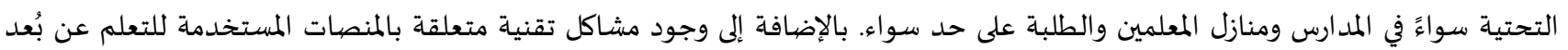

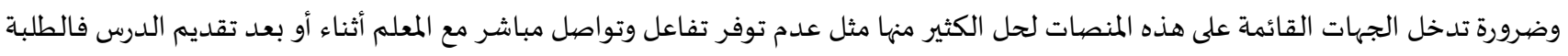

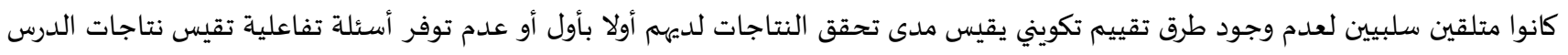

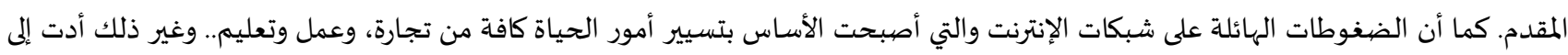

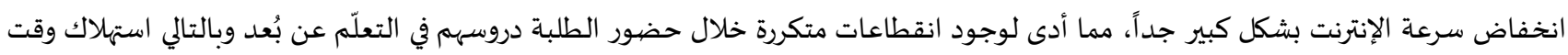

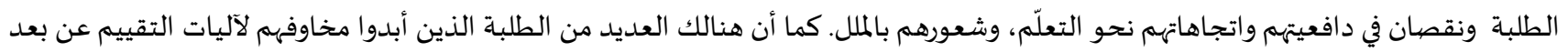

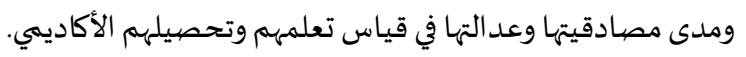
Amer, 2019 ; Abu Sarah, 2020 ; Hindi, 2020 ; Al-Atrubi, 2019 ; Bawaneh, ) تتفق نتيجة هذه الدراسة مع نتائج العديد من الدراسات (Martin, 2019 ; Glenda Kee, 20192020 ; Zhou., et. Al., 2020 الظروف الاستثنائية كالحروب والأوبئة. من جهة أخرى نجد العديد من الدراسات (Abu Aqel, Khleaf, 2020; Senteme, 2020 ; Mailizar, 2020 (Afouneh, 2020 ; Annelies Raes, 20202012 ; Al-Akharas, 2018 ;

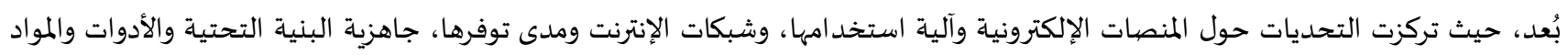

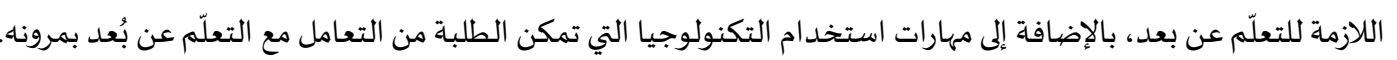

توصيات الدراسة ومقترحاتها: في ضوء نتاءج الدراسة وحددوها يوصي الباحث بما يلي:

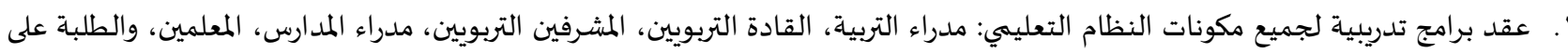

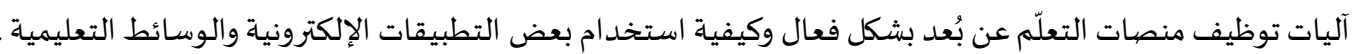

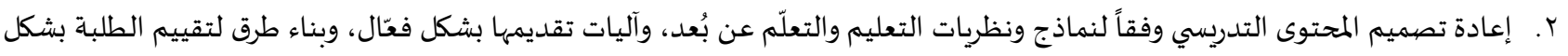
متوافق مع المخرجات وطرق التدريس. r. وضع جدول توزيع للحصص والتدريس عن بُعد بطريقة مرنة بحيث تراعي عدد من المتغيرات (وقت الطلبة، أعداد الطلبة، الأبناء الأخوة في الاسرة

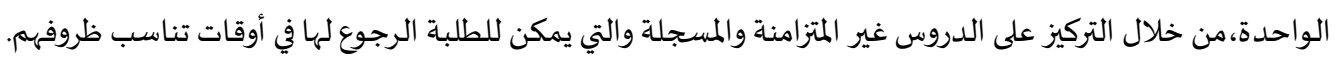

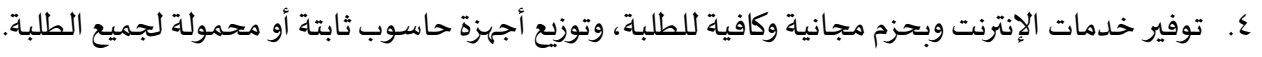

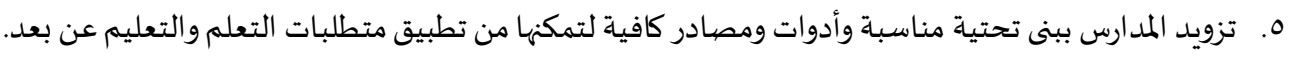
7. 


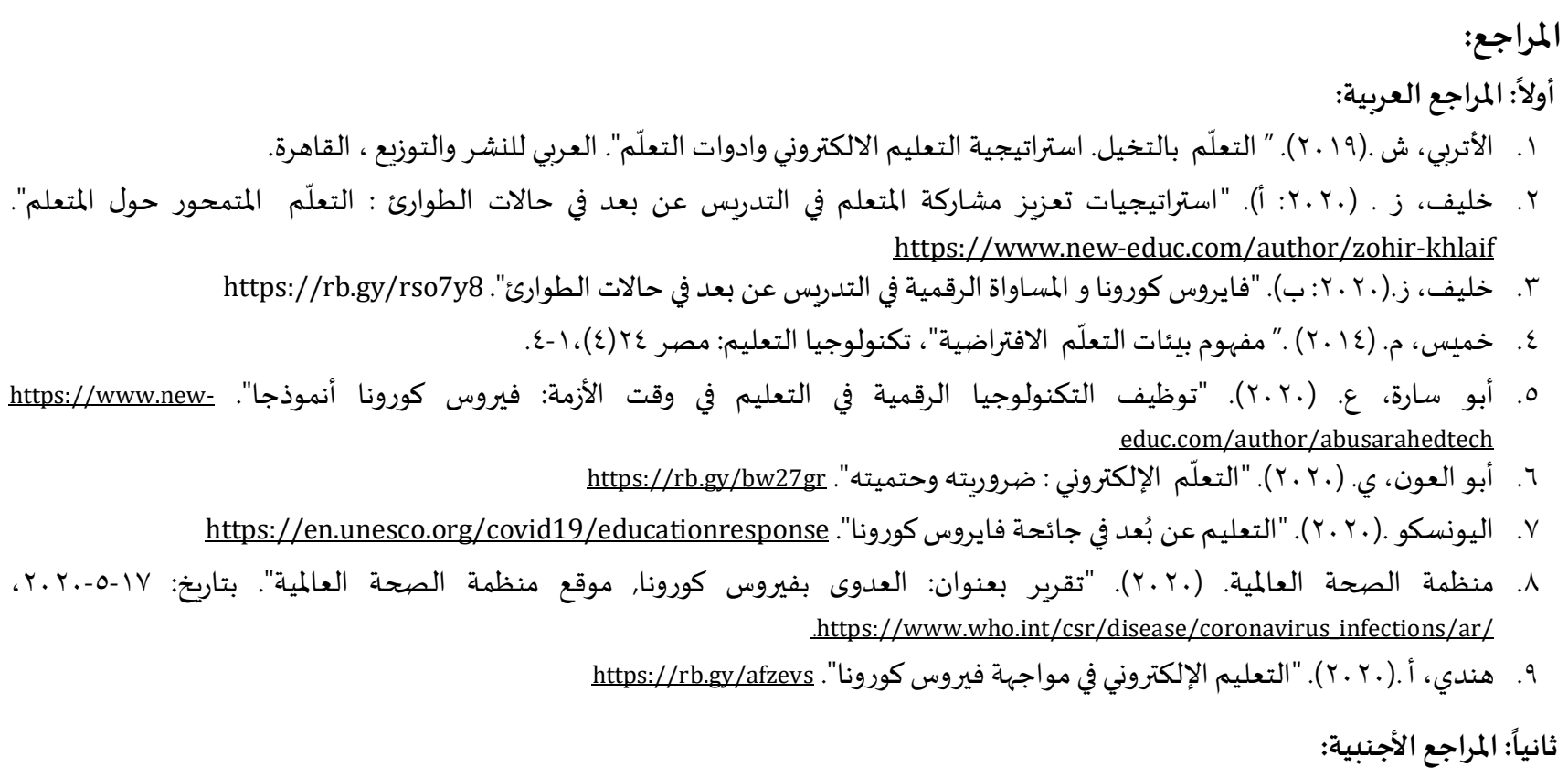

[1] Al-Akharas, Y. (2018). "The Impact of the Application of e-Learning Strategy on Academic Achievement in Mathematics in Basic Grades in the Capital Governorate from the Perspective of Teachers of Mathematics", Dirasat: Educational Sciences, 45(4): 70-80.

[2] Al-Kellani, A., \& Al-Shraifeen, N. (2011). "Introduction to research in educational and social sciences".”, Dar Almaisarah for publishing, distribution and printing. Amman, Jordan.

[3] Al-Shorman, B., \& Bawaneh, A. (2018). "Attitudes of Faculty Members and Students towards the Use of the Learning Management System in Teaching and Learning". The Turkish Online Journal of Educational Technology, 17 (3): 1-15. https://files.eric.ed.gov/fulltext/EJ1184192.pdf.

[4] Annelies, R., Pieter, V., Marieke, P., Ine, W., Wim, V., \& Fien, D. (2020). Learning and instruction in the hybrid virtual classroom: An investigation of students' engagement and the effect of quizzes. Computers \& Education. https://doi.org/10.1016/i.compedu.2019.103682.

[5] Abu Aqel, W. (2012). "The effect of using e-learning in teaching science on academic achievement for Al-Quds Open University students". Palestinian Journal of Open Education, 3(6): 115-138.

[6] Bawaneh, A. K., Moumene, A. B. H., \& Aldalalah, O. (2020). "Gauging the Level of Reflective Teaching Practices among Science Teachers". International Journal of Instruction, 13(1): 695-712. https://doi.org/10.29333/iji.2020.13145a.

[7] Bawaneh, A. K. A. (2020)." Science Teachers' Satisfaction Level of Professional Development Programs in Enhancing their Teaching Practices". Journal of Talent Development and Excellence, 12(3s): 1848-1865.

[8] Becker, S. A., Brown, M., Dahlstrom, E., Davis, A., DePaul, K., Diaz, V., \& Pomerantz, J. (2018). “NMC horizon report: 2018 higher education edition". Louisville, CO: Educause.

[9] Cho, M. H., \& Cho, Y. (2014). "Instructor scaffolding for interaction and students' academic engagement in online learning: Mediating role of perceived online class goal structures". The Internet and Higher Education, 21: 25-30. https://doi.org/10.1016/j.iheduc.2013.10.008.

[10] $\mathrm{Hu}, \mathrm{Q}$. (2019). "Review and Prospect: The Course and Future of the Development of Educational Informatization in China”. E-learn Edu, (12): 5-13.

[11] Huang, R. (2018). "Upgrading education informatization to help reform the education system”. Chin Edu News, (003): 519.

[12] Khlaif, Z., Nadiruzzaman, H., \& Kwon, K. (2017). "Types of Interaction in Online Discussion Forums: A Case Study". Journal of Educational Issues, 3(1): 155-169. https://doi.org/10.5296/jei.v3i1.10975.

[13] Kyungmee, L. (2020). "Coronavirus: universities are shifting classes online - but it's not as easy as it sounds". It was accessed on 22/03/2020. Website link: https://rb.gy/m7rfnk.

[14] Mailizar., Almanthari, A., Maulina, S., \& Bruce, S. (2020). “Secondary School Mathematics Teachers' Views on E-learning Implementation Barriers during the COVID-19 Pandemic: The Case of Indonesia". EURASIA Journal of Mathematics, Science and Technology Education, 16(7): em1860. https://doi.org/10.29333/ejmste/8240.

[15] Martin, J. (2019). "Building Relationships and Increasing Engagement in the Virtual Classroom: Practical Tools for the Online Instructor". Journal of Educators Online, 16(1). https://doi.org/10.9743/jeo.2019.16.1.9.

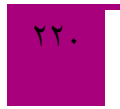

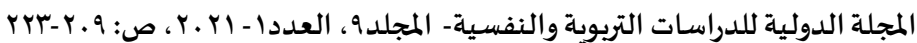


[16] Obiedat, D., Kayed, A., \& Adass, A. (2016). "Scientific research: understandable, tools and methods". Dar Alfiker: Publishers and distributors. Amman, Jordan.

[17] Olt, P. A. (2018). "Virtually there: Distant freshmen blended in classes through synchronous online education". Innovative Higher Education, 43(5): 381-395. https://doi.org/10.1007/s10755-018-9437-z.

[18] Saavedra, J.(2020). "Educational challenges and opportunities of the Coronavirus (COVID-19) pandemic". https://blogs.worldbank.org/education/educational-challenges-and-opportunities-covid-19-pandemic.

[19] Sintema, E. (2020). "Effect of COVID-19 on the Performance of Grade 12 Students: Implications for STEM Education". EURASIA Journal of Mathematics, Science and Technology Education, 16(7): 1-6. https://doi.org/10.29333/ejmste/7893.

[20] Zhou, L., Wu, Sh., Zhou, M \& Li, F. (2020). “School's Out, But Class' On', The Largest Online Education in the World Today: Taking China's Practical Exploration During The COVID-19 Epidemic Prevention and Control as an Example". Best Evid Chin Edu, 4(2), 501-519. https://doi.org/10.15354/bece.20.ar023. 
المجلة الدولية للدراسـات التربوية والنفسية

International Journal of Educational \& Psychological Studies (EPS)

Journal Homepage: https://www.refaad.com/views/EPSR/Home.aspx

www.refaad.com

ISSN: 2520-4149 (Online) 2520-4130 (Print)

\title{
Students' attitudes at basic and secondary classes in Jordan towards distance learning and the challenges they faced during Corona pandemic (COVID-19)
}

\author{
Subreen Mahmoud Al Salman \\ Training specialist at Queen Rania Teachers Academy \\ s.salman@qrta.edu.jo
}

Ali Khaled Ali Bawaneh

Deanship of Academic Development, Imam Abdulrahman Bin Faisal University, KSA akbawaneh@iau.edu.sa

Received : 18/6/2020 Revised : 30/6/2020 Accepted : 12/7/2020 DOI : https://doi.org/10.31559/EPS2021.9.1.13

Abstract: The study aimed to investigate the students' attitudes of basic and secondary schools in Jordan towards distance learning, the challenges they faced, and their suggestions to overcome them from their point of view. The study population included all Jordanian male and female students from all regions and for the various educational stages. The sample size of the study was (746) male and female students. The data was collected using a questionnaire that the researchers constructed and ensured its validity and reliability. The snowball method was used to spread out the questionnaire link. Appropriate statistical analyzes were performed to answer study questions such as means, standard deviations, frequencies, and percentages. The study concluded that the average attitudes of Jordanian students towards distance learning came within the intermediate category with mean (3.95) and (60\%) percentage, while the average of the challenges were within the weak category, which means there are many difficulties faced, with mean (2.14) and (36\%) percentage. The study also indicated that there are many challenges for distance learning in Jordanian schools represented in the availability and speed of Internet services, and content design according to distance learning, as well as the need to take into account the diversity of students and the method of delivering the material in addition to the importance of training both teachers and students on the mechanisms of using learning platforms. This study presented a set of recommendations drawn from the proposed solutions from the students themselves, including holding training programs for all members of the educational system, including teachers, and students on the mechanisms for employing distance learning platforms effectively, redesigning the content based on distance learning models and theories, and building assessment methods for students considering the alignment of learning outcomes, teaching methods, and assessment, setting and distribute a schedule for distance learning classes taking into account several variables, and providing Internet services with free and sufficient packages for students.

Keywords: Distance learning; students' attitudes; distance learning problems and solutions; learning in exceptional circumstances; Learning during COVID 19 Crisis.

\section{References:}

[1] Abw Al'wn, Y. (2020). "Alt'lm Alelktrwny: Drwryth Whtmyth". https://rb.gy/bw27gr.

[2] Alatrby, Sh .(2019). "Alt'lm Baltkhyl. Astratyjyh Alt'lym Alalktrwny Wadwat Alt'lm". Al'rby Llnshr Waltwzy' , Alqahrh.

[3] Hndy, A .(2020). "Alt'lym Alelktrwny Fy Mwajhh Fyrws Kwrwna". https://rb.gy/afzevs.

[4] Khlyf, Z . (2020: A). "Astratyjyat T'zyz Msharkh Almt'lm Fy Altdrys 'n B'd Fy Halat Altwar' : Alt'lm Almtmhwr Hwl Almt'lm". https://www.new-educ.com/author/zohir-khlaif

[5] Khlyf, Z.(2020: B). "Fayrws Kwrwna W Almsawah Alrqmyh Fy Altdrys 'n B'd Fy Halat Altwar'". https://rb.gy/rso7y8

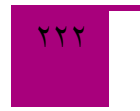

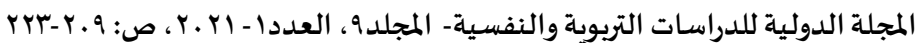


[6] Khmys, M. (2014). "Mfhwm By'at Alt'lm Alaftradyh", Tknwlwjya Alt'lym: Msr 24(4),1-4.

[7] Mnzmh Alshh Al'almyh. (2020). "Tqryr B'nwan: Al'dwa Bfyrws Kwrwna, Mwq' Mnzmt Alshh Al'almyh". Btarykh: 17-52020, https://www.who.int/csr/disease/coronavirus_infections/ar/.

[8] Abw Sarh, '. (2020). "Twzyf Altknwlwjya Alrqmyh Fy Alt'lym Fy Wqt Alazmh: Fyrws Kwrwna Anmwdja". https://www.new-educ.com/author/abusarahedtech.

[9] Alywnskw .(2020). "Alt'lym 'n Bu'd Fy Ja'ht Fayrws Kwrwna". https://en.unesco.org/covid19/educationresponse. 